\title{
Infant Irritability, AE
}

National Cancer Institute

\section{Source}

National Cancer Institute. Infant Irritability, AE. NCI Thesaurus. Code C154939.

An adverse event in a newborn characterized by crying easily and difficulty consoling. 